\title{
Proposta de um método para avaliação da percepção de valor de técnicos e de usuários em Habitação de Interesse Social
}

\author{
Proposal of a method to evaluate technicians' and users' \\ value perception in social housing
}

\section{Deyvid Aléx de Bitencourt Monteiro Luciana Inês Gomes Miron}

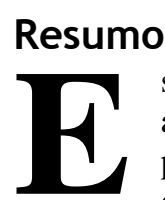
método envolveu a estruturação de um questionário, planejamento amostral, coleta e análise de dados. O método foi implementado e aprimorado durante três estudos, nos quais foram avaliados EHIS do Programa Integrado Entrada da Cidade (PIEC) em Porto Alegre, RS. A principal contribuição da pesquisa é referente à proposta do Método de Avaliação, o qual é operacionalizado a partir de três fases. A primeira fase tem como objetivo a identificação dos níveis que compõem o mapeamento hierárquico de valor esperado e a customização do instrumento de coleta de dados. A segunda fase tem como objetivo a construção de um protocolo de coleta, análise e processamento de dados. A terceira fase tem como objetivo a análise combinada dos dados da pesquisa e a comparação entre o valor esperado pelos técnicos e o recebido pelos usuários por meio do mapeamento hierárquico de valor e da disseminação dos resultados para melhoria de futuros empreendimentos. Entre os principais resultados desta pesquisa estão a identificação de benefícios percebidos pelos usuários e não esperados pelos técnicos e a explicitação dos níveis mais abstratos presentes na percepção dos usuários, os quais traduzem o objetivo utilizado em programas habitacionais brasileiros.

Palavras-chave: Método de avaliação. Percepção de valor. Empreendimentos Habitacionais de Interesse Social (EHIS).

\begin{abstract}
This paper presents a method to evaluate the perceived value expected by technicians from public institutions and received by users of Brazilian social housing. The development of the method involved the structuring of a questionnaire, a sample design, data collection and analysis. The method was implemented and enhanced during three studies that evaluated social housing projects from the Programa Integrado Entrada da Cidade (PIEC) in Porto Alegre, $R S$, Brazil. The main contribution of the study is the proposition of an evaluation

method, which is operated in three stages. The first stage aims to identify the levels that make up a hierarchical mapping of expected value and the customization of the data collection tool. The second stage aims to build a protocol for the collection, analysis and processing of data. The third stage consists of a combined analysis research data and the comparison between the value expected by technicians and that perceived by the users through a hierarchical value mapping, and the dissemination of the results to improve future projects. The main results of this study include the identification of benefits perceived by users but not expected by technicians, as well as an explanation of the more abstract levels present in users' perceptions, which translate the objective used in Brazilian housing programs.

Keywords: Evaluation method. Perception of value. Social housing (EHIS in portuguese).
\end{abstract}

Deyvid Aléx de Bitencourt

Monteiro

Universidade Federal do Rio Grande

Porto Alegre - RS - Brasil

Luciana Inês Gomes Miron Universidade Federal do Rio Grande Porto Alegre - RS - Brasil

Recebido em 19/05/17 Aceito em 25/08/17 


\section{Introdução}

A avaliação de empreendimentos tem grande importância no esforço de melhoria da habitação de interesse social, podendo auxiliar na avaliação de resultados diante dos objetivos de programas habitacionais brasileiros (BONATTO; MIRON; FORMOSO, 2011). Diante disso, e também considerando os recursos públicos e privados investidos na habitação de interesse social, autores têm destacado a importância da formação da geração de valor para os usuários, a fim de que os resultados gerados ocorram de forma adequada e duradoura (BONATTO, 2010; BRITO; FORMOSO; ROCHA, 2012; HENTSCHKE et al., 2014; BRITO; FORMOSO, 2014).

$\mathrm{Na}$ busca de um referencial teórico mais consistente para o conceito de geração de valor, pesquisadores têm buscado, em distintos campos do conhecimento, referenciais teóricos que auxiliem no entendimento e em sua aplicação no contexto do ambiente construído (KOSKELA, 2000; LEINONEN; HUOVILA, 2000; BARLOW; OZAKI, 2003; MIRON, 2008; BONATTO, 2010; BRITO; FORMOSO; ROCHA, 2012). A área de marketing, por sua vez, tem se destacado pela evolução na mensuração de importantes constructos relacionados à geração de valor, tais como satisfação, valor percebido, benefícios e retenção (MIRON; FORMOSO, 2009; MIRON; TZORTZOPOULOS; FORMOSO, 2013).

Woodruff (1997), pesquisador da área de marketing, salienta que o valor é gerado diante de situações de uso, vinculando atributos de produtos e seu desempenho às consequências de uso e aos objetivos (ou valores pessoais). A ideia de relacionar os atributos e consequências de uso do produto aos objetivos é ancorada em uma estrutura conceitual denominada de Mapa de Hierarquia de Valor (MHV), o qual inclui o valor percebido antes (valor esperado) e após o uso de determinado produto (valor recebido). Segundo o mesmo autor, o valor esperado pode ser considerado na perspectiva de uma organização, enquanto o valor recebido, na perspectiva do usuário do produto (WOODRUFF, 1997).

A estrutura conceitual proposta por Woodruff (1997) é fundamentada no modelo Means-End Chain (MEC) ou Modelo de Cadeia Meios-Fim (GUTMAN, 1982). Para Khalifa (2004), esse modelo preenche uma lacuna na literatura de valor ao esclarecer por que os usuários conferem distintos pesos nas avaliações de um produto. Segundo Reynolds e Olson (2008), o Modelo atua conectando os atributos concretos de um produto aos valores pessoais dos usuários por meio de uma cadeia cognitiva que possui seis níveis de abstração: (a) atributos concretos;

(b) atributos abstratos;

(c) consequências funcionais;

(d) consequências psicossociais;

(e) valores instrumentais; e

(f) valores terminais.

Diante do potencial de contribuição do Modelo de Cadeia Meios-Fim para a compreensão e estruturação dos níveis abstratos presentes na percepção dos usuários, esse modelo tem sido utilizado como fundamentação teórica para algumas pesquisas com foco na avaliação do ambiente construído, especificamente de empreendimentos habitacionais de interesse social (EHIS) (MIRON, 2008; MIRON; FORMOSO, 2009; GRANJA et al., 2009; BONATTO, 2010). Tais pesquisas têm apresentado contribuições para o entendimento do valor percebido pelos beneficiários de EHIS ao explorar por meio de MHV o valor percebido pelos usuários após o uso desses empreendimentos (valor recebido)

No entanto, a revisão desses estudos permite inferir que, apesar das contribuições para o entendimento do valor recebido pelos usuários, ainda persistem algumas lacunas relacionadas, sobretudo, ao entendimento do valor esperado pelas organizações envolvidas no desenvolvimento de EHIS. De modo adicional, a análise dessas pesquisas também permite evidenciar algumas limitações referentes aos instrumentos de coleta e análise de dados empregados, os quais resultaram em um entendimento do valor recebido pelo usuário ainda limitado aos níveis de atributos e consequências de uso do produto habitação de interesse social (SILVA, 2015; MONTEIRO et al., 2015).

Nesse contexto, buscando contribuir com os estudos existentes, a presente pesquisa combina, por meio de MHV, o conceito de valor esperado e recebido. Nesta pesquisa o valor esperado pela organização é representado pela percepção dos técnicos envolvidos no desenvolvimento de EHIS. O valor recebido, por sua vez, é definido como sendo a avaliação dos usuários (moradores) em relação aos atributos recebidos de um EHIS, às consequências de uso e a seus objetivos (ou valores pessoais). Parte-se do pressuposto de que a abordagem da percepção de valor de ambas as esferas (técnicos e moradores) por meio de um método de hierarquia de valor tenda a contribuir para a visualização dos resultados que estão ou não sendo alcançados pelos programas habitacionais brasileiros. 
Quanto às limitações referentes aos instrumentos de coleta e análise de dados, a presente pesquisa parte do pressuposto de que técnicas de pesquisa mais adequadas para o MHV poderiam facilitar a coleta, análise e disseminação de resultados. Entre as técnicas de pesquisa existentes, a laddering tem sido amplamente aplicada em pesquisas do ambiente construído (COOLEN; HOEKSTRA, 2001; VELUDO-DE-OLVEIRA; IKEDA, 2005; ZINAS; JUSAN, 2012; HENTSCHKE et al., 2014; BRITO; FORMOSO, 2014; SILVA, 2015; MARQUES, 2015). A técnica de pesquisa laddering é constituída por entrevistas em profundidade (coleta), identificação de ladders (análise) e representação dos dados no MHV (interpretação), na abordagem do modelo de Cadeias Meios-Fim (REYNOLDS; GUTMAN, 1988).

A partir do exposto, este artigo tem como objetivo apresentar um método proposto para avaliação da percepção de valor esperado pelos técnicos de instituições públicas e recebido pelos usuários (moradores) de empreendimentos habitacionais de interesse social (EHIS) brasileiros. A pertinência desta pesquisa situa-se na necessidade de avançar no conhecimento acerca dos métodos de avaliação que possibilitem uma visualização mais clara dos resultados alcançados por EHIS, tendo como base a combinação dos resultados esperados (técnicos) e os efetivamente recebidos (usuários). O presente artigo faz parte de uma pesquisa de mestrado (MONTEIRO, 2015) que procura dar continuidade e trazer contribuições às sucessivas avaliações que têm abordado a percepção de valor no ambiente construído (MIRON, 2008; MIRON; FORMOSO, 2009; MONTEIRO et al., 2015; MONTEIRO; MIRON, 2016, 2017).

\section{Método}

Para o desenvolvimento deste estudo adotou-se a estratégia de pesquisa construtiva (constructive research ou design research). Segundo Lukka (2003), essa estratégia de pesquisa caracteriza-se por:

(a) foco em problemas do mundo real com relevância de serem resolvidos na prática;

(b) produção de um artefato inovador de forma a resolver esses problemas;

(c) tentativa de implementação do artefato desenvolvido para testar a aplicabilidade;

(d) estreito envolvimento e cooperação entre pesquisador e profissionais, possibilitando a aprendizagem baseada na experiência; (e) associação explícita ao conhecimento teórico prévio; e

(f) especial atenção à reflexão dos resultados, retornando para a teoria.

Visando a um aprofundamento sobre o contexto de pesquisa, inicialmente se buscou encontrar um problema com potencial relevância prática e teórica para a presente pesquisa. O objetivo desta etapa foi compreender o contexto, o problema e os objetivos a serem investigados.

Posteriormente, desenvolveu-se um modelo conceitual para guiar a avaliação. Para tanto, buscou-se operacionalizar conceitos da área de marketing, principalmente sobre a hierarquia de valor. Como parte do modelo, foi identificado um conjunto de constructos para representar a percepção dos técnicos sobre EHIS em uso, que serviram de ponto de partida para o desenvolvimento de um instrumento de coleta de dados.

O conjunto de constructos e o instrumento de coleta de dados foram gerados a partir de dados de pesquisas anteriores (MIRON, 2008; MIRON; FORMOSO, 2009; BONATTO, 2010) e de reuniões realizadas com os técnicos da Prefeitura Municipal de Porto Alegre (PMPA). As seções do questionário foram reorganizadas a partir de dois testes piloto, que objetivavam melhorar a consistência interna do instrumento de coleta, assim como facilitar a relação pesquisador-respondente.

Durante o processo de construção do Método de Avaliação foram realizadas três apresentações, as quais originaram discussões e contribuições para essa fase da pesquisa. As discussões foram realizadas com técnicos envolvidos no desenvolvimento dos empreendimentos e com pesquisadores do Programa de Pós-Graduação em Planejamento Urbano e Regional da Universidade Federal do Rio Grande do Sul (Propur) e do Núcleo Orientado para inovação da edificação da Universidade Federal do Rio Grande do Sul (Norie) com experiência em avaliações de percepção de valor de empreendimentos habitacionais de interesse social (EHIS).

Como parte do processo de desenvolvimento e aprimoramento do Método de Avaliação foram realizados três estudos empíricos de forma sequencial em distintos EHIS do PIEC. Essa diversidade de EHIS avaliados foi uma necessidade da pesquisa, uma vez que o modelo de avaliação não deveria estar focado em um programa habitacional específico. Para tanto, foram definidos juntamente com técnicos os empreendimentos avaliados na pesquisa, apresentados no Quadro 1. 
Para a implementação do Método de Avaliação nos três objetos empíricos selecionados, desenvolveu-se um instrumento de coleta. Consideraram-se como população de cada empreendimento apenas as unidades habitacionais ocupadas. Após o cálculo do tamanho da amostra, a aplicação dos questionários foi realizada de forma presencial pelas equipes de coleta, que visitaram os EHIS e entrevistaram os moradores das unidades habitacionais préselecionadas por meio de amostra aleatória simples. O Quadro 2 apresenta a coleta de dados nos empreendimentos investigados.

Para a análise dos dados obtidos foram utilizados os softwares Statistical Package for the Social Sciences $\left(\right.$ SPSS $\left.^{\circledR}\right)$, Excel $^{\circledR}$ e LadderUX. Para a análise dos dados quantitativos da presente pesquisa foram realizadas as técnicas estatísticas de frequência, análise de correspondência, de resíduos ajustados e Kruskal-Wallis. Para análise dos dados qualitativos da pesquisa obtidos por meio da técnica laddering foram seguidas as etapas recomendadas por Reynolds e Gutman (1988):

(a) análise de conteúdo;

(b) construção da matriz de implicação;

(c) construção do mapa de hierarquia de valor e; (d) determinação das orientações de percepções dominantes por meio de um ponto de corte que deve representar cerca de dois terços (2/3 ou $66 \%)$ de todas as relações da matriz de implicação.

Os pontos de corte utilizados nesta pesquisa foram representados e indicados nos MHV correspondente a cada estudo realizado.

\section{Resultados da avaliação}

Os principais resultados a serem apresentados neste artigo são referentes às contribuições do método proposto para a avaliação.

\section{Método de Avaliação}

O Método de Avaliação foi estruturado a partir de três fases:

(a) preparação da avaliação;

(b) implementação da avaliação e análise de resultados; e

(c) discussão e disseminação dos resultados.

As fases e os resultados de sua implantação são descritas na sequência.

Quadro 1 - Empreendimentos e programas habitacionais dos estudos realizados

\begin{tabular}{|c|c|c|c|c|c|}
\hline EHIS & Tempo de ocupação & Tipologia & População (N) & Amostra (n) & Localização \\
\hline \multirow{2}{*}{ ESTUDO 1} & \multirow{2}{*}{8 anos } & Sobrados & $\mathrm{N}=57$ & $\mathrm{~N}=36$ & \multirow{2}{*}{ Porto Alegre/RS } \\
\hline & & UHPNE & $\mathrm{N}=1$ & $\mathrm{~N}=1$ & \\
\hline \multirow{2}{*}{ ESTUDO 2} & \multirow{2}{*}{7 anos } & Sobrados & $\mathrm{N}=116$ & $\mathrm{~N}=52$ & \multirow{2}{*}{ Porto Alegre/RS } \\
\hline & & Térreas & $\mathrm{N}=12$ & $\mathrm{~N}=11$ & \\
\hline \multirow{3}{*}{ ESTUDO 3} & \multirow{3}{*}{6 anos } & Sobrados & $\mathrm{N}=168$ & $\mathrm{~N}=61$ & \multirow{3}{*}{ Porto Alegre/RS } \\
\hline & & Térreas & $\mathrm{N}=20$ & $\mathrm{~N}=17$ & \\
\hline & & UHPNE & $\mathrm{N}=2$ & $\mathrm{~N}=2$ & \\
\hline
\end{tabular}

Quadro 2 - Empreendimentos e programas habitacionais dos estudos realizados

\begin{tabular}{|c|l|l|l|l|}
\hline \multicolumn{1}{|c|}{ EHIS } & \multicolumn{1}{|c|}{ Equipe } & \multicolumn{1}{c|}{ Data da Coleta } & Horário da Coleta & Tempo de duração \\
\hline ESTUDO 1 & $\begin{array}{l}\text { Seis pessoas } \\
\text { organizadas em } \\
\text { três duplas }\end{array}$ & $\begin{array}{l}\text { 21 e 23 de outubro } \\
\text { de 2015 (terça-feira } \\
\text { e quarta-feira) }\end{array}$ & 14h às 17h & $\begin{array}{l}20 \text { min para cada } \\
\text { questionário }\end{array}$ \\
\hline ESTUDO 2 & $\begin{array}{l}\text { Seis pessoas } \\
\text { organizadas em } \\
\text { três duplas }\end{array}$ & $\begin{array}{l}\text { 25 e 27 de outubro } \\
\text { de 2015 (sábado e } \\
\text { segunda-feira) }\end{array}$ & $14 \mathrm{~h}$ às 17h & $\begin{array}{l}15 \text { min para cada } \\
\text { questionário }\end{array}$ \\
\hline ESTUDO 3 & $\begin{array}{l}\text { Duas pessoas } \\
\text { organizadas em } \\
\text { uma dupla }\end{array}$ & $\begin{array}{l}\text { 30 e 31 de outubro } \\
\text { (quinta-feira e } \\
\text { sexta-feira) }\end{array}$ & 14h às 17h & $\begin{array}{l}10 \text { min para cada } \\
\text { questionário }\end{array}$ \\
\hline
\end{tabular}




\section{Primeira fase do método: preparação da avaliação}

A primeira fase do método consiste no ajuste do modelo conceitual às particularidades do empreendimento a ser avaliado a partir de um MHV que representa as percepções dos técnicos (valor esperado). Nesse MHV foram identificados os atributos do EHIS (passo 1), as consequências de uso desse empreendimento (passo 2) e os objetivos esperados (passo 3). A estruturação desses níveis foi realizada a partir de banco de dados identificados em pesquisas existentes (MIRON, 2008; MIRON; FORMOSO, 2009; BONATTO, 2010), e com base na percepção dos técnicos envolvidos no desenvolvimento dos empreendimentos.

De forma complementar, também foram realizadas análises sobre documentos específicos dos empreendimentos a serem avaliados, os quais originaram novos constructos para avaliação. Esses novos constructos foram comparados com a literatura pertinente a fim de identificar sua posição em relação aos níveis de abstração que compõem o modelo de hierarquia de valor. Após a adição dos níveis ao modelo conceitual, o questionário (ou instrumento de coleta a ser utilizado) foi adaptado (passo 4).

As seções que compõem o instrumento de coleta foram utilizadas para estruturação do questionário. Ao questionário foi acrescentada a técnica laddering, a qual permite a abordagem de dados qualitativos a partir de entrevistas em profundidade realizadas com os usuários. Para definição do questionário foram realizadas reuniões com os técnicos envolvidos no desenvolvimento dos empreendimentos, assim como a validação dele por meio do Alpha de Cronbach.

A Figura 1 apresenta a primeira fase do Método de Avaliação, descrevendo de forma ilustrativa cada fase que deve ser seguida para a preparação da avaliação.

A Figura 2 apresenta como exemplo a hierarquia de valor esperado estruturada com base na percepção dos técnicos envolvidos no desenvolvimento do empreendimento avaliado no estudo 1 .

De modo geral, na estruturação do MHV do estudo 1 alguns aspectos foram mais evidenciados pelos técnicos da PMPA do que outros (ver linhas mais espessas no mapa de hierarquia de valor esperado). No tocante ao atributo concreto "unidade habitacional", tais aspectos se referem à adequação dos espaços ao uso, à qualidade construtiva e ao conforto ambiental da unidade habitacional. Quanto ao atributo concreto "empreendimento", os técnicos relacionaram os atributos abstratos à "qualidade da infraestrutura e dos serviços urbanos", ao "projeto social" e à "gestão de uso". Em relação ao atributo concreto "entorno urbano", foram relacionados à "qualidade e ao uso dos equipamentos urbanos". No topo do modelo, como valor instrumental, foi adicionado o objeto principal do programa como sendo a "melhoria da qualidade de vida dos usuários".

\section{Figura 1 - Primeira fase do Método}




Figura 2 - Modelo de hierarquia de valor do estudo 1

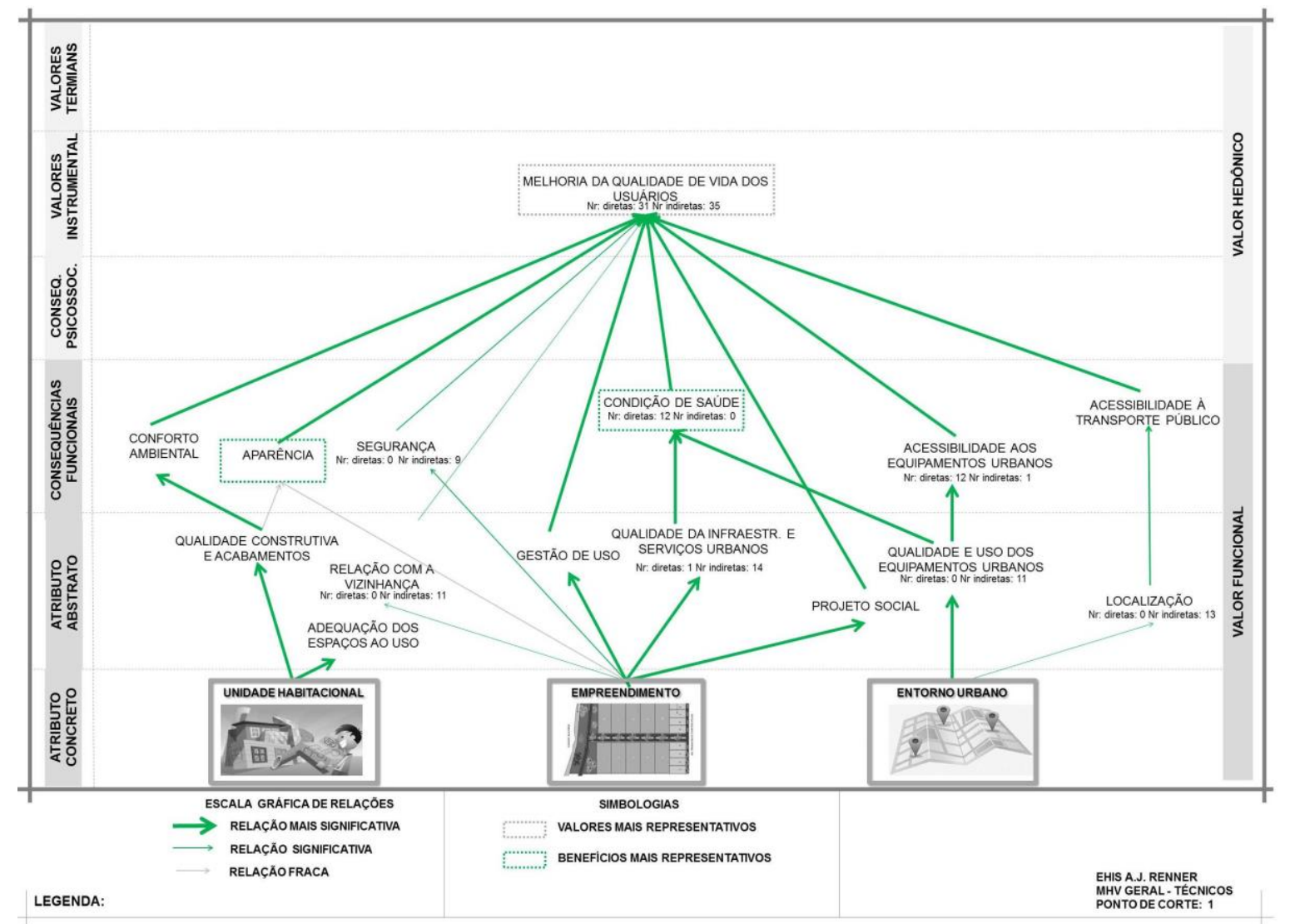

No mapeamento de hierarquia de valor esperado pelos técnicos a consequência funcional de "aparência" aparece vinculada aos atributos concretos "unidade habitacional" e "empreendimento". A consequência funcional de "segurança", por sua vez, aparece vinculada apenas ao empreendimento. Já a "condição de saúde" aparece vinculada tanto ao atributo concreto "empreendimento", por meio da consequência funcional "qualidade da infraestrutura e dos serviços urbanos", quanto pelo atributo concreto "entorno urbano", por meio da "qualidade e uso dos equipamentos urbanos" e sua fácil "acessibilidade".

De modo adicional, observou-se durante as reuniões realizadas com os técnicos que os atributos concretos do EHIS não tendem a possuir grande variabilidade, sendo compreendidos basicamente a partir da unidade habitacional, do empreendimento e do entorno urbano. Os atributos abstratos, por sua vez, podem variar de acordo com o empreendimento. Neste caso, optou-se por utilizar os atributos abstratos do EHIS de forma genérica, sendo necessária a revisão deles a cada avaliação realizada.

De modo similar aos atributos do EHIS, as consequências de uso também podem variar de acordo com o empreendimento avaliado. Neste sentido, optou-se por construir um banco de consequências de uso genéricas, as quais podem ser acrescentadas ou extraídas de acordo com o EHIS avaliado, permitindo, neste caso, que o modelo mantenha certa flexibilidade, o que acaba por tornar a contribuição do método mais abrangente para a avaliação de futuros empreendimentos.

No âmbito dos programas habitacionais estudados, constatou-se que os EHIS têm como objetivo principal a melhoria da qualidade de vida dos usuários. Um ponto importante a ser considerado em relação a esse objetivo é que o significado de melhoria da qualidade de vida tende a ser bastante amplo e vago, podendo variar de acordo com o EHIS avaliado. Logo, há a necessidade de revisão dos objetivos a cada EHIS avaliado tendo em vista que tais objetivos são influenciados pelo contexto dos empreendimentos.

Em um momento posterior à construção da hierarquia de valor esperado pelos técnicos foi estruturado o instrumento de coleta. Do mesmo modo que a hierarquia de valor esperado, o instrumento de coleta também tende a apresentar características específicas do empreendimento. Nesse caso, a cada EHIS avaliado as consequências 
de uso esperadas pelos técnicos da PMPA são identificadas, sendo acrescentadas ou retiradas consequências de uso de acordo com a necessidade de avaliação do empreendimento.

A Figura 3 apresenta como modelo parte da seção de satisfação do instrumento de coleta de dados genérico utilizado para realizar as avaliações nos três estudos realizados.

A Figura 4 apresenta como exemplo parte da seção de satisfação do instrumento de coleta de dados já adaptado para avaliação do estudo 1 tendo como base a hierarquia de valor esperado pelos técnicos (Figura 2).

\section{Figura 3 - Seção 2: Satisfação dos usuários com os projetos}

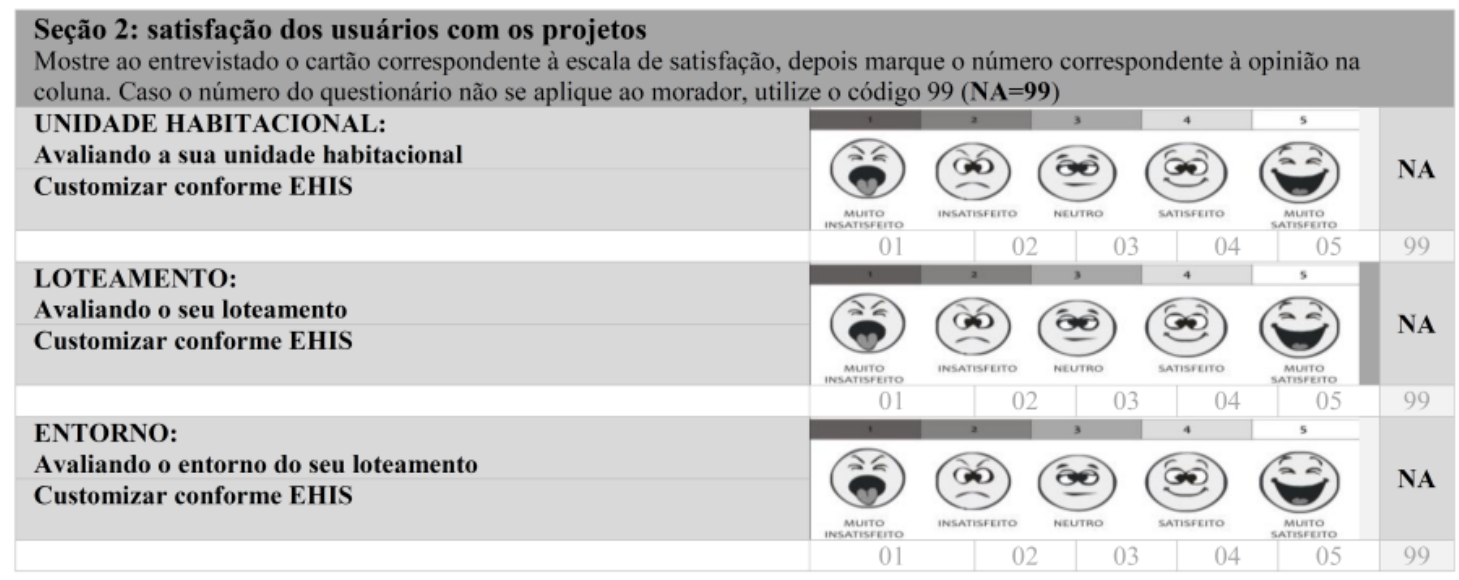

\section{Figura 4 - Seção 2: Satisfação dos usuários com os projetos}

\begin{tabular}{|c|c|c|c|c|c|c|}
\hline \multicolumn{7}{|c|}{$\begin{array}{l}\text { Seção 2: satisfação dos usuários com os projetos } \\
\text { Mostre ao entrevistado o cartão correspondente à escala de satisfação, depois marque o número correspondente à opinião na } \\
\text { coluna. Caso o número do questionário não se aplique ao morador, utilize o código } 99(\mathbf{N A = 9 9 )}\end{array}$} \\
\hline $\begin{array}{l}\text { UNIDADE HABITACIONAL: } \\
\text { Avaliando a sua residência } \\
\text { Qualidade da unidade habitacional } \\
\text { Como você se sente com relação à/ao: }\end{array}$ & 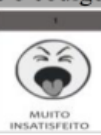 & (12. & 1 & 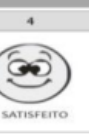 & itiono & NA \\
\hline $\begin{array}{l}1 \text { Espaço físico da sua UH (sala, cozinha, quarto, banheiro e área de } \\
\text { serviço) }\end{array}$ & 01 & 02 & 03 & 04 & 05 & 99 \\
\hline 2 Espaço físico do pátio da sua unidade habitacional (frente e fundos) & 01 & 02 & 03 & 04 & 05 & 99 \\
\hline $\begin{array}{l}3 \text { Qualidade construtiva da sua unidade habitacional (materiais } e \\
\text { acabamentos) }\end{array}$ & 01 & 02 & 03 & 04 & 05 & 99 \\
\hline 4 Conforto ambiental da sua unidade habitacional (térmico e acústico) & 01 & 02 & 03 & 04 & 05 & 99 \\
\hline 5 Aparência da sua unidade habitacional & 01 & 02 & 03 & 04 & 05 & 99 \\
\hline LOTEAMENTO: & & & - & 4 & $s$ & \\
\hline Avaliando o seu loteamento & & & & & & NA \\
\hline $\begin{array}{l}\text { Qualidade do loteamento } \\
\text { Como você se sente com relação ao/aos: }\end{array}$ & $\begin{array}{l}\text { Murro } \\
\text { Aitspeir }\end{array}$ & risfer & & & & $\mathbf{N A}$ \\
\hline 1 Uso de praças (espaços públicos do loteamento) & 01 & 02 & 03 & 04 & 05 & 99 \\
\hline 2 Espaço físico do lugar que você mora & 01 & 02 & 03 & 04 & 05 & 99 \\
\hline 3 Relação com a vizinhança & 01 & 02 & 03 & 04 & 05 & 99 \\
\hline $\begin{array}{l}4 \text { Sensação de segurança do seu loteamento durante o dia (crimes e } \\
\text { assaltos) }\end{array}$ & 01 & 02 & 03 & 04 & 05 & 99 \\
\hline $\begin{array}{l}5 \text { Sensação de segurança do seu loteamento durante a noite (crimes e } \\
\text { assaltos) }\end{array}$ & 01 & 02 & 03 & 04 & 05 & 99 \\
\hline 6 Aparência do lugar que você mora & 01 & 02 & 03 & 04 & 05 & 99 \\
\hline ENTORNO: & & & 3 & 4 & s & \\
\hline Avaliando o entorno do seu loteamento & & & & & & NA \\
\hline $\begin{array}{l}\text { Qualidade do entorno urbano } \\
\text { Como você se sente com relação ao/aos: }\end{array}$ & 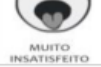 & & & & & NA \\
\hline 1 Uso dos parques (espaços públicos dos arredores) & 01 & 02 & 03 & 04 & 05 & 99 \\
\hline 2 Localização do seu loteamento & 01 & 02 & 03 & 04 & 05 & 99 \\
\hline 3 Acessibilidade aos equipamentos urbanos & 01 & 02 & 03 & 04 & 05 & 99 \\
\hline 4 Acessibilidade ao seu loteamento (transporte coletivo) & 01 & 02 & 03 & 04 & 05 & 99 \\
\hline 5 Sensação de segurança nos arredores do seu lot. durante o dia & 01 & 02 & 03 & 04 & 05 & 99 \\
\hline 6 Sensação de segurança nos arredores do seu lot. durante a noite & 01 & 02 & 03 & 04 & 05 & 99 \\
\hline
\end{tabular}


A partir da apresentação da preparação do Método de Avaliação, a pesquisa segue para a fase de implementação da avaliação nos três estudos empíricos para testar a aplicabilidade do método proposto, os quais contemplaram ciclos de preparação, implementação, análise e disseminação dos principais resultados com os técnicos, conforme apresentado na sequência.

\section{Segunda fase do método: implementação da avaliação e análise dos resultados}

A segunda fase do método consiste na coleta, análise, processamento e análise dos dados. Nesta fase da pesquisa foram definidos os empreendimentos a serem avaliados, assim como a população-alvo da pesquisa (passo 1). Para a delimitação dos empreendimentos e da populaçãoalvo foram realizadas análises de documentos específicos sobre os empreendimentos, os quais continham informações atualizadas, assim como reuniões com os técnicos envolvidos no desenvolvimento desses empreendimentos.

Na preparação para coleta de dados (passo 2) foram realizados contatos prévios com os líderes comunitários dos empreendimentos a serem investigados visando definir a data mais apropriada para a coleta de dados. Após a definição da data, foram realizados treinamentos com toda a equipe de avaliação, incluindo pesquisadores e técnicos envolvidos no desenvolvimento dos empreendimentos. Após o treinamento para a coleta de dados, a implementação da avaliação foi realizada (passo 3).
A tabulação dos dados resultantes da avaliação foi realizada pelo pesquisador com o auxílio de um estatístico (passo 4). Os dados resultantes foram divididos em dois bancos de dados: quantitativos e qualitativos. Os dados quantitativos foram analisados por meio do software SPSS ${ }^{\circledR}$ (passo 5), enquanto os dados quantitativos (técnica laddering) foram analisados por meio da ferramenta LadderUX. Para a análise dos dados resultantes da técnica laddering foram seguidos os passos recomendados na literatura da área de marketing.

A Figura 5 apresenta a segunda fase do Método de Avaliação e descreve detalhadamente cada fase a ser seguida para a implementação e análise dos resultados da avaliação.

A implementação da avaliação envolveu a mobilização de uma equipe de pesquisa. Para a análise dos dados qualitativos da técnica laddering contou-se com o auxílio de um grupo de pesquisadores do Propur e do Norie. Os resultados da avaliação dos três estudos foram analisados e discutidos individualmente e de forma comparativa.

A Tabela 1 apresenta uma compilação com os principais resultados da avaliação nos três estudos realizados nesta pesquisa.

De modo geral, foram observados índices altos de satisfação com o EHIS nos três estudos realizados na presente pesquisa. Entre os maiores índices de satisfação evidenciados nos empreendimentos destacam-se os serviços de infraestrutura urbana, tais como o fornecimento de água e o fornecimento de energia elétrica. Já em relação aos índices de insatisfação, destacam-se o conforto ambiental da unidade habitacional e o espaço físico do empreendimento para estacionamento e áreas de lazer.

Figura 5 - Segunda fase do Método

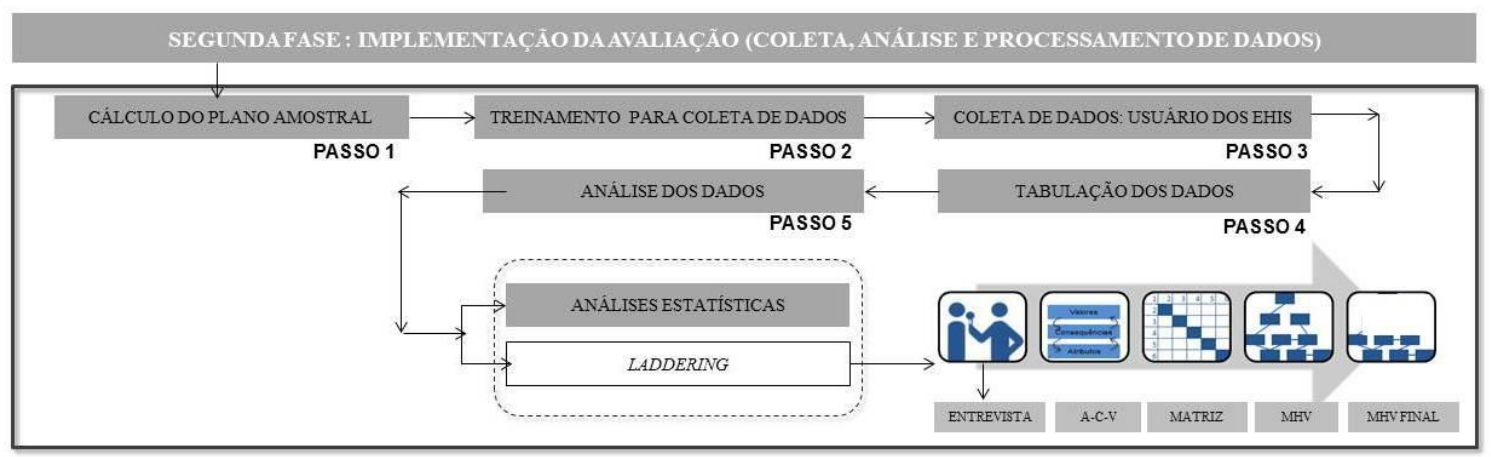


Tabela 1 - Resumo das avaliações dos EHIS investigados

\begin{tabular}{|c|c|c|c|}
\hline EHIS & ESTUDO 1 & ESTUDO 2 & ESTUDO 3 \\
\hline \multicolumn{4}{|c|}{ SATISFAÇÃO COM O PRODUTO EHIS } \\
\hline $\begin{array}{l}\text { Maior índice de } \\
\text { satisfação }(\%)\end{array}$ & $\begin{array}{l}\text { Fornecimento de água }(97,3 \%) \\
\text { Fornecimento de luz }(97,3 \%)\end{array}$ & $\begin{array}{l}\text { Fornecimento de água } \\
(98,4 \%)\end{array}$ & $\begin{array}{l}\text { Fornecimento de luz } \\
\qquad(97,5 \%)\end{array}$ \\
\hline $\begin{array}{l}\text { Maior índice de } \\
\text { insatisfação }(\%)\end{array}$ & Conforto ambiental $(59,5 \%)$ & $\begin{array}{l}\text { Espaço físico do } \\
\text { empreendimento } \\
(76,3 \%)\end{array}$ & $\begin{array}{l}\text { Espaço físico do } \\
\text { empreendimento } \\
(76,3 \%)\end{array}$ \\
\hline \multicolumn{4}{|c|}{ MELHORIAS REALIZADAS E PRETENDIDAS FUTURAMENTE } \\
\hline Modificadas (\%) & $84 \%$ & $98 \%$ & $95 \%$ \\
\hline $\begin{array}{l}\text { Melhorias realizadas } \\
(\%)\end{array}$ & $\begin{array}{l}\text { Acessórios de proteção e } \\
\text { vedação verticais }(21 \%)\end{array}$ & $\begin{array}{l}\text { Revestimentos } \\
\text { verticais }(25 \%) \text {, }\end{array}$ & $\begin{array}{l}\text { Revestimentos } \\
\text { verticais }(24 \%)\end{array}$ \\
\hline Pretensão (\%) & $68 \%$ & $70 \%$ & $72 \%$ \\
\hline $\begin{array}{l}\text { Melhorias pretendidas } \\
(\%)\end{array}$ & Categoria "outros" (24\%) & $\begin{array}{l}\text { Revestimentos } \\
\text { verticais }(25 \%)\end{array}$ & $\begin{array}{l}\text { Revestimentos } \\
\text { verticais }(29 \%)\end{array}$ \\
\hline \multicolumn{4}{|c|}{$\begin{array}{l}\text { MOTIVOS DA NÃO PERMANÊNCIA DA FAMÍLIA ORIGINALMENTE REASSENTADA NO } \\
\text { EHIS }\end{array}$} \\
\hline Não permanência & Não permaneceram (11\%) & $\begin{array}{l}\text { Não permaneceram } \\
(30 \%)\end{array}$ & $\begin{array}{l}\text { Não permaneceram } \\
(28 \%)\end{array}$ \\
\hline $\begin{array}{l}\text { Motivos para não } \\
\text { permanência }\end{array}$ & $\begin{array}{c}\text { Problemas de adaptação à } \\
\text { unidade habitacional (25\%) } \\
\text { Probl. entre os vizinhos }(25 \%) \\
\text { Valorização imobiliária }(25 \%) \\
\text { Problemas de saúde }(25 \%)\end{array}$ & $\begin{array}{c}\text { Valorização imobiliária } \\
\qquad(26,3 \%)\end{array}$ & $\begin{array}{c}\text { Valorização } \\
\text { imobiliária }(54,5 \%)\end{array}$ \\
\hline \multicolumn{4}{|c|}{$\begin{array}{l}\text { MOTIVOS PARA A ATUAL FAMÍLIA PERMANECER OU NÃO NO EHIS NOS PRÓXIMOS } \\
\text { ANOS }\end{array}$} \\
\hline $\begin{array}{l}\text { Intenção de } \\
\text { permanência }(\%)\end{array}$ & Intenção de permanecer (59\%) & $\begin{array}{c}\text { Intenção de } \\
\text { permanecer }(67 \%)\end{array}$ & $\begin{array}{c}\text { Intenção de } \\
\text { permanecer }(72 \%)\end{array}$ \\
\hline $\begin{array}{l}\text { Motivos para } \\
\text { permanecer }(\%)\end{array}$ & $\begin{array}{l}\text { Segurança do empreendimento } \\
\qquad(31,8 \%)\end{array}$ & $\begin{array}{l}\text { Familiaridade com o } \\
\quad \text { lugar }(33,3 \%)\end{array}$ & $\begin{array}{l}\text { Familiaridade com o } \\
\text { lugar }(22,4 \%)\end{array}$ \\
\hline $\begin{array}{l}\text { Intenção de não } \\
\text { permanência }(\%)\end{array}$ & $\begin{array}{c}\text { Intenção de não permanecer } \\
(41 \%)\end{array}$ & $\begin{array}{c}\text { Intenção de não } \\
\text { permanecer }(33 \%)\end{array}$ & $\begin{array}{c}\text { Intenção de não } \\
\text { permanecer }(28 \%)\end{array}$ \\
\hline $\begin{array}{l}\text { Motivos para não } \\
\text { permanecer }(\%)\end{array}$ & $\begin{array}{l}\text { Problemas de adaptação à } \\
\text { unidade habitacional (60\%) }\end{array}$ & $\begin{array}{c}\text { Problemas de } \\
\text { adaptação à unidade } \\
\text { habitacional }(66,7 \%)\end{array}$ & $\begin{array}{c}\text { Problemas de } \\
\text { adaptação à unidade } \\
\text { habitacional }(81,8 \%)\end{array}$ \\
\hline \multicolumn{4}{|c|}{ MAPA DE HIERARQUIA DE VALOR - ATRIBUTOS DO PRODUTO EHIS } \\
\hline $\begin{array}{l}\text { Atributo mais } \\
\text { representativo ( } n^{\circ} \text { de } \\
\text { relações) }\end{array}$ & Empreendimento (rd.47|ri.138) & $\begin{array}{l}\text { Entorno urbano } \\
\text { (rd.69|ri.199) }\end{array}$ & $\begin{array}{l}\text { Entorno urbano } \\
(\text { rd.102|ri.253) }\end{array}$ \\
\hline $\begin{array}{l}\text { Atributo menos } \\
\text { representativo }\left(n^{0} \text { de }\right. \\
\text { relações })\end{array}$ & $\begin{array}{l}\text { Unidade habitacional } \\
\text { (rd.18|ri.32) }\end{array}$ & $\begin{array}{l}\text { Unidade habitacional } \\
\text { (rd.32|ri.56) }\end{array}$ & $\begin{array}{l}\text { Unidade habitacional } \\
\qquad(\text { rd.24|ri.45) }\end{array}$ \\
\hline \multicolumn{4}{|c|}{ MAPA DE HIERARQUIA DE VALOR - CONSEQUÊNCIAS DE USO OU BENEFÍCIOS DO EHIS } \\
\hline $\begin{array}{l}\text { Consequência de uso } \\
\text { mais mencionada ( }{ }^{\circ} \\
\text { de relações) }\end{array}$ & $\begin{array}{l}\text { Relação entre a vizinhança } \\
\text { (rd.20|ri.53) }\end{array}$ & $\begin{array}{l}\text { Acessibilidade aos } \\
\text { equipamentos urbanos } \\
\text { (rd.35|ri.57) }\end{array}$ & $\begin{array}{l}\text { Acessibilidade aos } \\
\text { equipamentos } \\
\text { urbanos (rd.47|ri.75) }\end{array}$ \\
\hline $\begin{array}{l}\text { Consequência de uso } \\
\text { menos mencionada (no } \\
\text { de relações) }\end{array}$ & $\begin{array}{c}\text { Adequação dos espaços aos } \\
\text { usos (rd.1/ri.1) }\end{array}$ & $\begin{array}{l}\text { Adequação dos } \\
\text { espaços aos usos } \\
\text { (rd.4|ri.4) }\end{array}$ & $\begin{array}{l}\text { Adequação dos } \\
\text { espaços aos usos } \\
\text { (rd.6|ri.2) }\end{array}$ \\
\hline \multicolumn{4}{|c|}{ MAPA DE HIERARQUIA DE VALOR - VALORES } \\
\hline $\begin{array}{l}\text { Valor mais } \\
\text { mencionado (no de } \\
\text { relações) }\end{array}$ & $\begin{array}{l}\text { Igualdade de direitos } \\
\quad \text { (rd.15|ri.42) }\end{array}$ & $\begin{array}{l}\text { Senso de realização } \\
\quad(\text { rd.38|ri.133) }\end{array}$ & $\begin{array}{l}\text { Senso de realização } \\
\quad(\text { rd.32|ri.89) }\end{array}$ \\
\hline $\begin{array}{l}\text { Valor menos } \\
\text { mencionado (no de } \\
\text { relações) }\end{array}$ & Felicidade (rd.0/ri.11) & $\begin{array}{l}\text { Prosperidade } \\
\text { (rd.16|ri.32) }\end{array}$ & $\begin{array}{l}\text { Igualdade de direitos } \\
\quad \text { (rd.15|ri.32) }\end{array}$ \\
\hline
\end{tabular}


No que se refere às modificações realizadas nas unidades habitacionais, grande parte dos usuários mencionou já ter realizado alguma alteração. Entre as principais modificações destacam-se a categoria de acessórios de proteção e vedação verticais, tais como grades e muros, e a categoria de revestimentos verticais, tais como pintura $\mathrm{e}$ revestimentos cerâmicos internos e externos. Já em relação à pretensão de modificações destacam-se a categoria outros, tais como a troca de esquadrias, e a categoria de revestimentos verticais. Entre a categoria de revestimentos verticais a pintura foi a mais mencionada e tende a estar relacionada à necessidade de manutenção da unidade habitacional como consequência do tempo de ocupação.

Nos empreendimentos avaliados foi possível observar a predominância de mulheres como responsáveis pela família. Esse resultado evidencia uma tendência possivelmente relacionada ao fato de o programa priorizar a concessão de títulos a mulheres como responsáveis pelas famílias. Quanto ao grau de escolaridade, é possível observar a predominância de responsáveis com primeiro grau completo nos empreendimentos. Esse resultado é um indicador positivo, uma vez que no estudo de Miron (2008) predominavam os responsáveis com primeiro grau incompleto ${ }^{1}$. Outro dado interessante nas avaliações é o acesso dos responsáveis ao curso superior, especialmente no estudo 2, o qual evidenciou que $6 \%$ desses responsáveis estavam, até o momento da avaliação, matriculadas em universidades da capital gaúcha.

No tocante à permanência das famílias, foi possível observar índices positivos nos empreendimentos avaliados. A sensação de segurança no empreendimento e a familiaridade com o local representam os principais motivos para a permanência das famílias originalmente reassentadas nos empreendimentos avaliados. Por outro lado, os principais motivos para a não permanência das famílias no empreendimento estão relacionados, de forma predominante, aos problemas de adaptação à unidade habitacional.

Quanto à intenção de permanência da atual família nos empreendimentos avaliados, foram observados índices bastante altos, principalmente nos estudos 2 e $3,67 \%$ e $72 \%$ respectivamente. Entre os principais motivos dessa intenção destacam-se a sensação de segurança no empreendimento e a familiaridade com o lugar. Já em relação aos motivos para a não permanência da atual família nos empreendimentos avaliados foi mencionada, de forma predominante, a inadequação dos espaços aos usos desses atuais usuários da unidade habitacional.

${ }^{1}$ A autora avaliou três EHIS do mesmo programa (Piec) e identificou a predominância de responsáveis com primeiro grau
Entre os principais resultados dos mapas de hierarquia de valor pode-se inferir que no estudo 1 o atributo concreto "empreendimento" está relacionado aos principais benefícios percebidos pelos usuários e aos motivos mais representativos para a permanência deles no empreendimento (Figura 6). A análise dos estudos 2 e 3 permite inferir que o atributo concreto "entorno urbano" está relacionado aos benefícios mais percebidos pelos usuários e consequentemente aos motivos mais representativos para a permanência deles nos empreendimentos (Figuras 7 e 8, respectivamente). Já o atributo concreto "unidade habitacional" está relacionado aos benefícios menos percebidos pelos usuários, aos maiores índices de insatisfação e, consequentemente, aos principais motivos para a não permanência das famílias nos três estudos realizados, representando, portanto, a principal oportunidade de melhoria nos EHIS investigados.

\section{Terceira fase do método: discussão e disseminação dos resultados}

A terceira e última fase do método consiste na apresentação, discussão e disseminação de resultados. O primeiro passo recomendado nesta fase do método se refere à análise comparativa do MHV de valor esperado construído com base na percepção dos técnicos na fase de preparação da avaliação e do MHV de valor recebido construído com base na percepção dos usuários como resultado da adição da técnica laddering ao instrumento de coleta (passo 1).

Essa análise comparativa foi embasada em formas representativas claras que possibilitaram uma abordagem ampla dos resultados da avaliação (passo 2), facilitando a transmissão de conhecimento para possível melhoria de futuros empreendimentos. Após a representação visual, os resultados foram apresentados e discutidos com os potenciais utilizadores das informações resultantes, ou seja, com os técnicos envolvidos no desenvolvimento dos empreendimentos avaliados.

As informações resultantes foram analisadas pelos técnicos e disseminadas a fim de possibilitar sua utilização. Caso a forma de apresentação dos resultados seja de difícil leitura pelos técnicos, novos refinamentos na forma de apresentação desses resultados devem ser realizados nesta fase do método. Durante as discussões dos resultados com os técnicos foram realizados esforços para que a retroalimentação dos dados e melhoria de futuros empreendimentos possa ser realizada.

incompleto: Vila Tecnológica (71,42\%), Pôr-do-Sol (55,35\%) e Progresso $(55,88)$ (MIRON, 2008). 
Figura 6 - Hierarquia de valor recebido do estudo 1

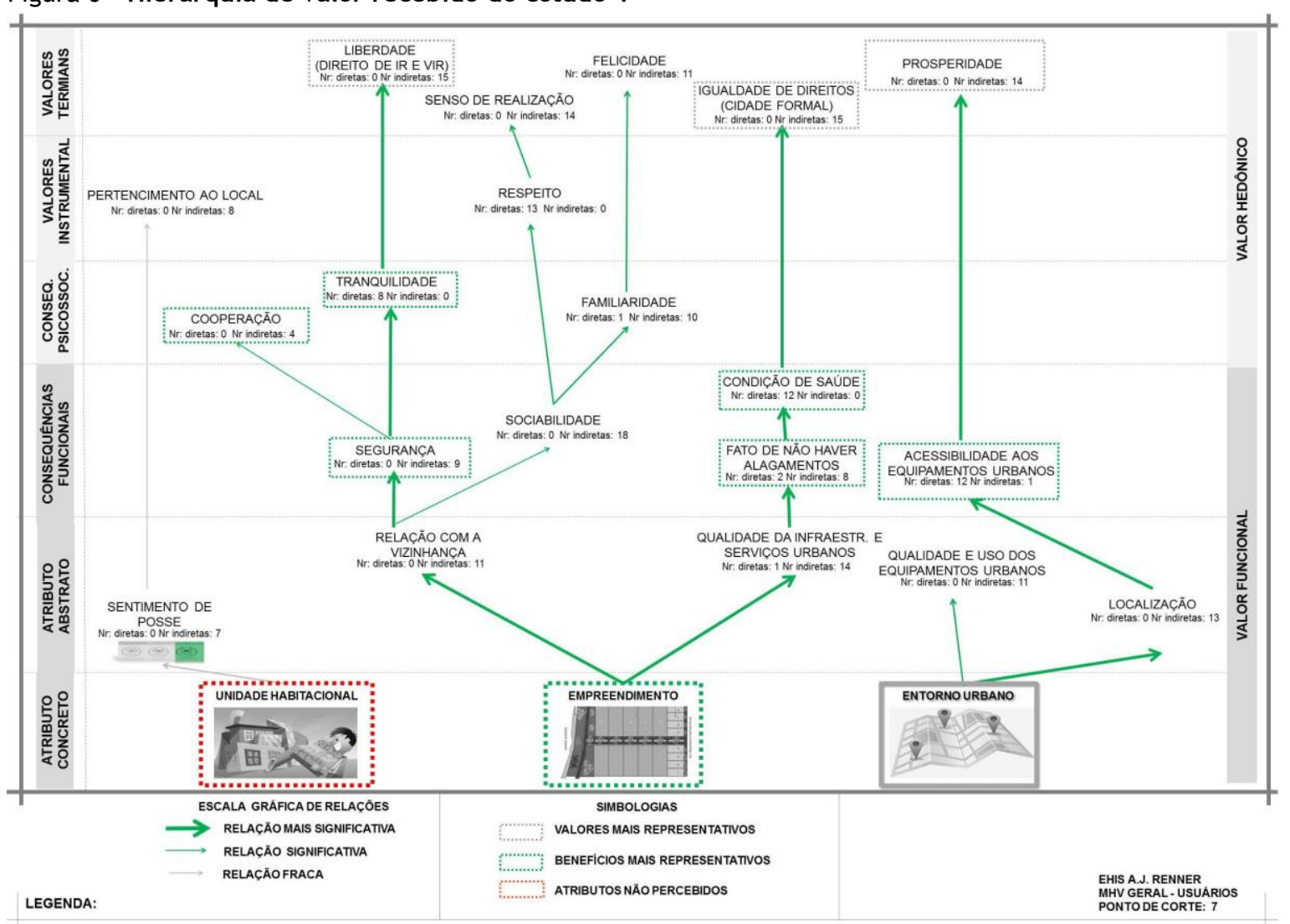

Figura 7 - Hierarquia de valor recebido do estudo 2

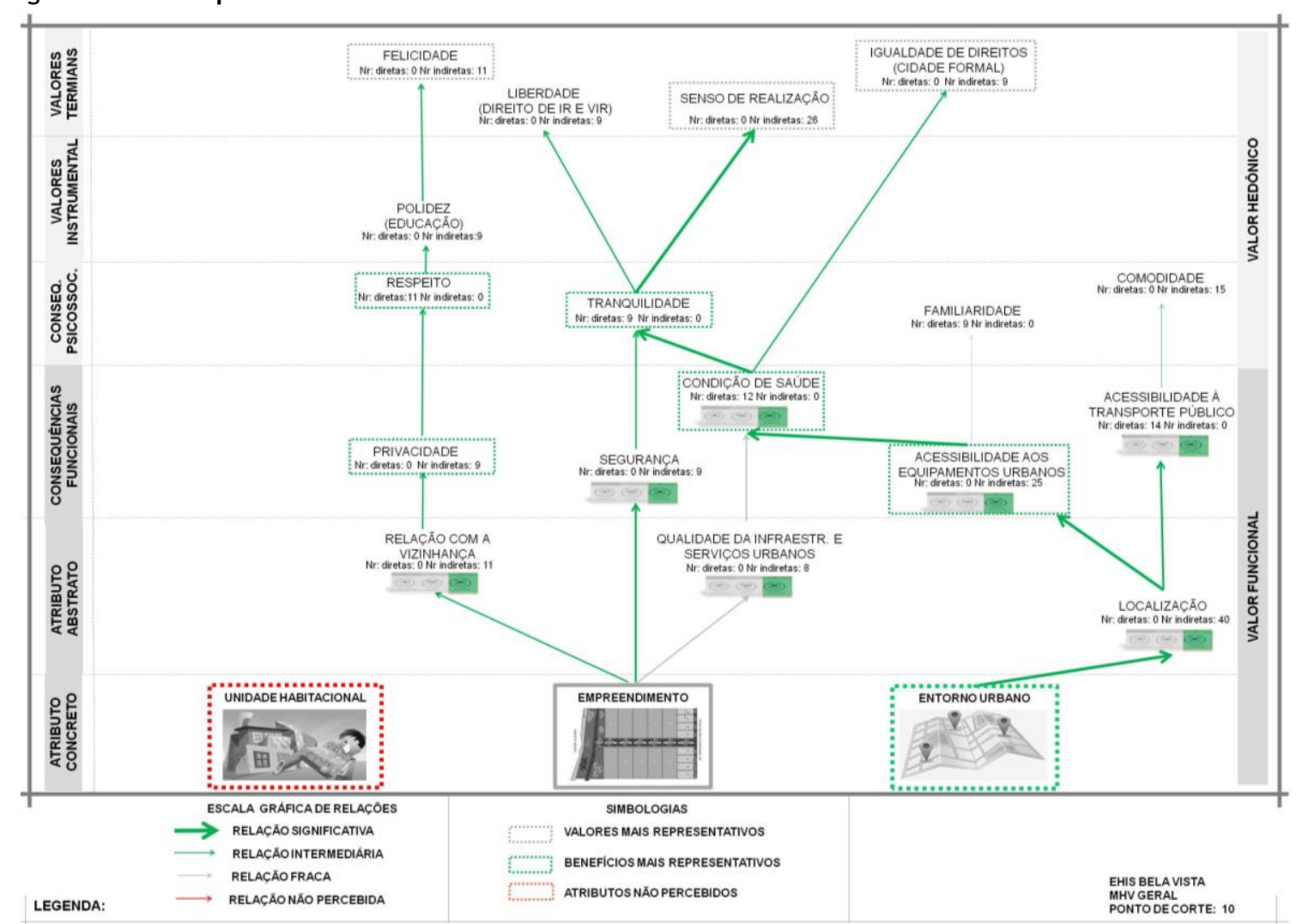


Figura 8 - Hierarquia de valor recebido do estudo 3

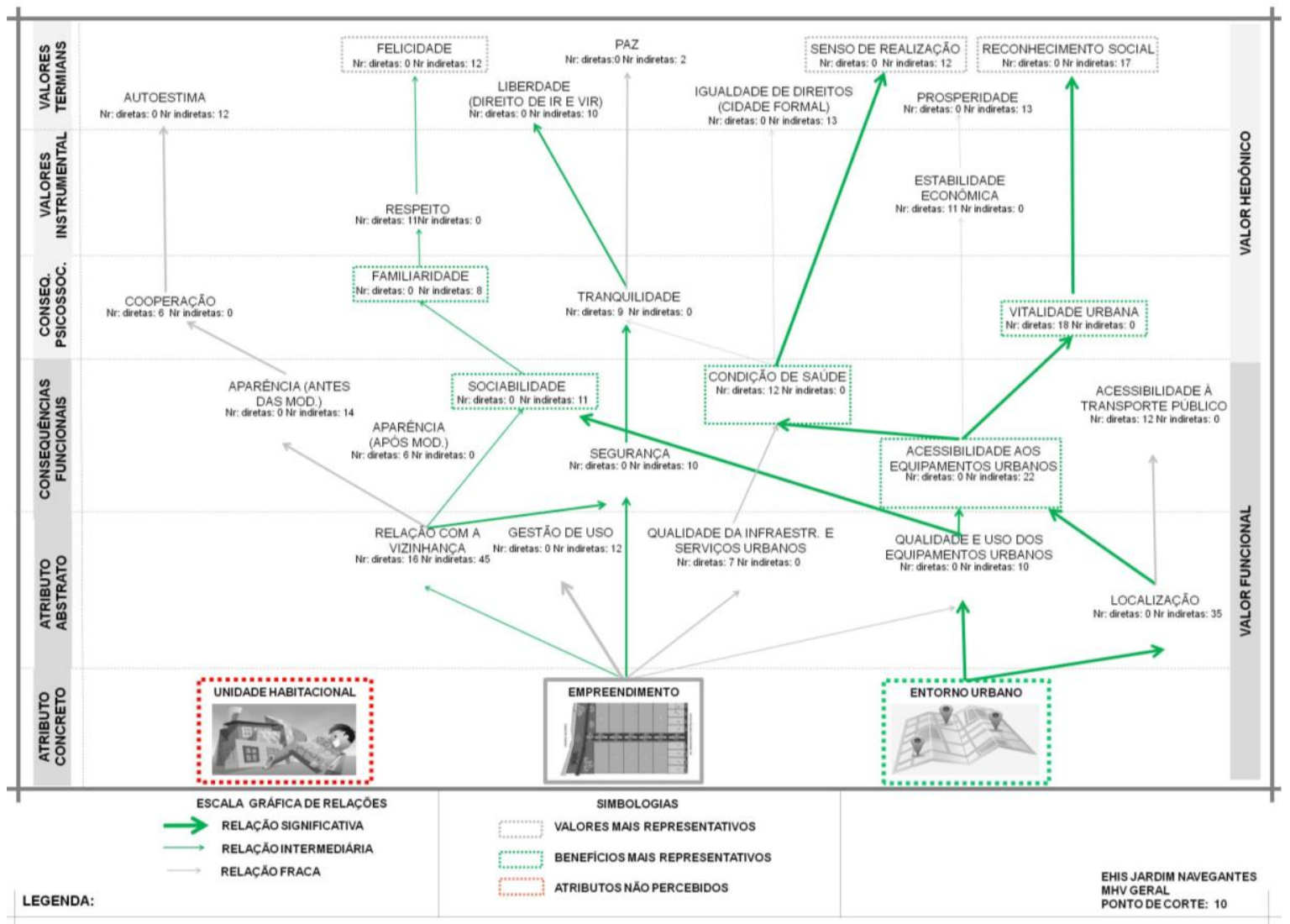

Figura 9 - Terceira fase do Método

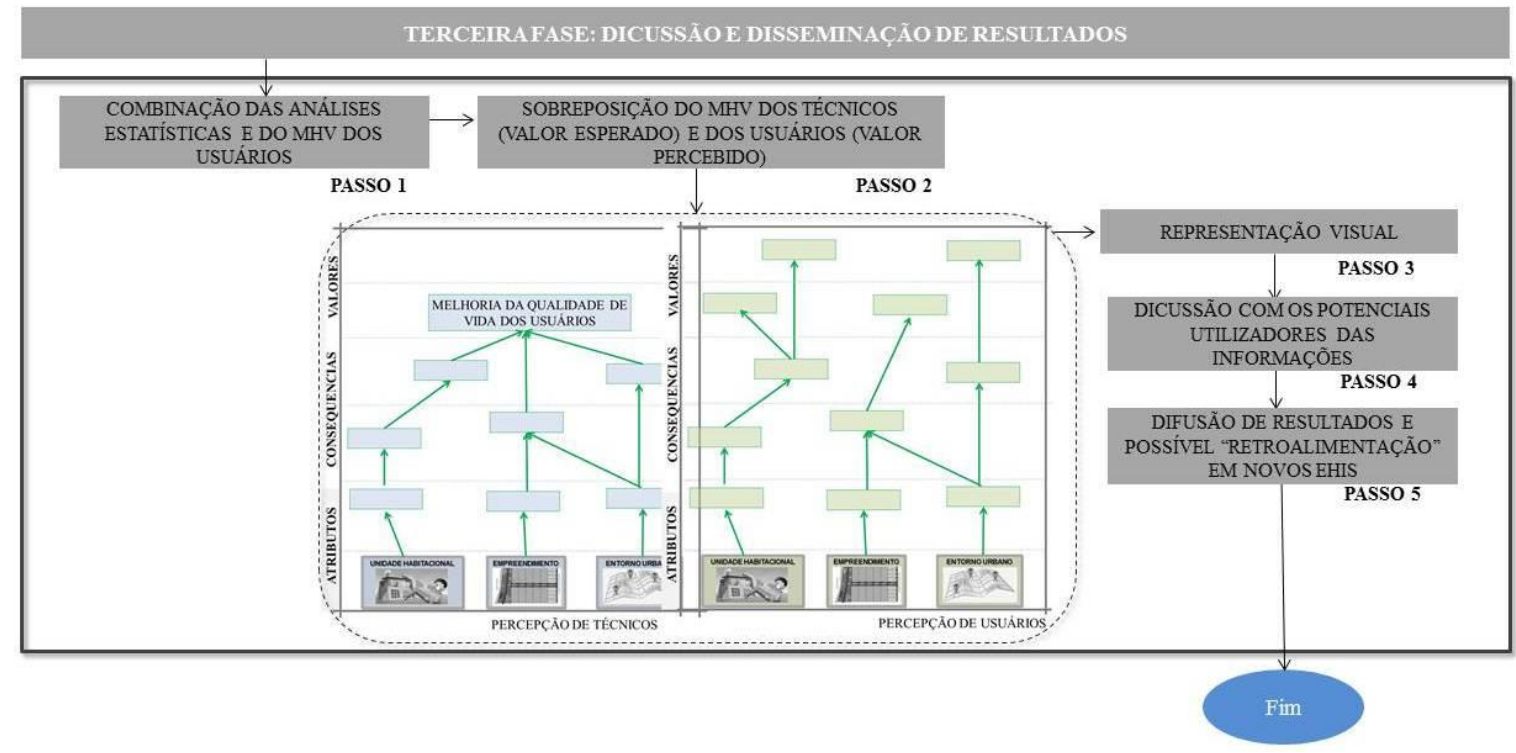

A Figura 9 apresenta a terceira fase do Método de Avaliação e descreve detalhadamente cada fase que deve ser seguida para a discussão e disseminação dos resultados da pesquisa.
A discussão e disseminação dos resultados envolveu a participação dos técnicos envolvidos no desenvolvimento dos empreendimentos avaliados. Nesta fase da pesquisa os mapas de hierarquia de valor esperado (técnicos) e recebido (usuários) 
foram sobrepostos a fim de verificar as divergências e as convergências entre as percepções de ambas as esferas. Além dos mapas de hierarquia de valor provenientes dos dados qualitativos da pesquisa, buscou-se também integrar os dados quantitativos da seção de satisfação dos usuários, conforme pode ser observado nas Figuras 10 (estudo 1), 11 (estudo 2) e 12 (estudo 3 ).

As diferentes percepções dos técnicos da PMPA e dos usuários acerca do mesmo EHIS ficaram mais evidenciadas a partir da estruturação dos mapas de hierarquia de valor dos empreendimentos avaliados. Bonatto (2010) explica que mesmo EHIS que apresentem atributos, consequência de uso e objetivos similares, podem resultar em diferentes relações nas avaliações, o que evidencia mapeamentos de hierarquia específicos para cada empreendimento, como é o caso desta pesquisa.

Entre os principais resultados dessa análise integrada pode-se inferir que no estudo $1 \mathrm{o}$ atributo concreto "empreendimento" está relacionado aos principais benefícios percebidos pelos usuários e aos motivos mais representativos para a permanência deles no EHIS. A análise dos estudos 2 e 3 permite inferir que o atributo concreto “entorno urbano" está relacionado aos benefícios mais percebidos pelos usuários e, consequentemente, aos motivos mais representativos para a permanência deles nos empreendimentos. Já o atributo concreto "unidade habitacional" está relacionado aos benefícios menos percebidos pelos usuários, aos maiores índices de insatisfação e, consequentemente, aos principais motivos para a não permanência da atual família nos três estudos realizados, o que representa a principal oportunidade de melhoria no EHIS investigado.

Cabe salientar que nas hierarquias de valor resultantes dos empreendimentos avaliados foi possível identificar benefícios percebidos pelos usuários que não haviam sido mencionados pelos técnicos da PMPA na preparação da avaliação. Do mesmo modo, benefícios que eram esperados pelos técnicos da Prefeitura não foram percebidos pelos usuários, principalmente os relacionados à unidade habitacional. Um ponto importante a ser considerado nas avaliações é que os benefícios esperados pelos técnicos da PMPA e percebidos pelos usuários são os que apresentaram os maiores índices de satisfação, estando ainda associados ao surgimento de cadeias cognitivas mais significativas.

Figura 10 - Resultado geral da avaliação do estudo 1

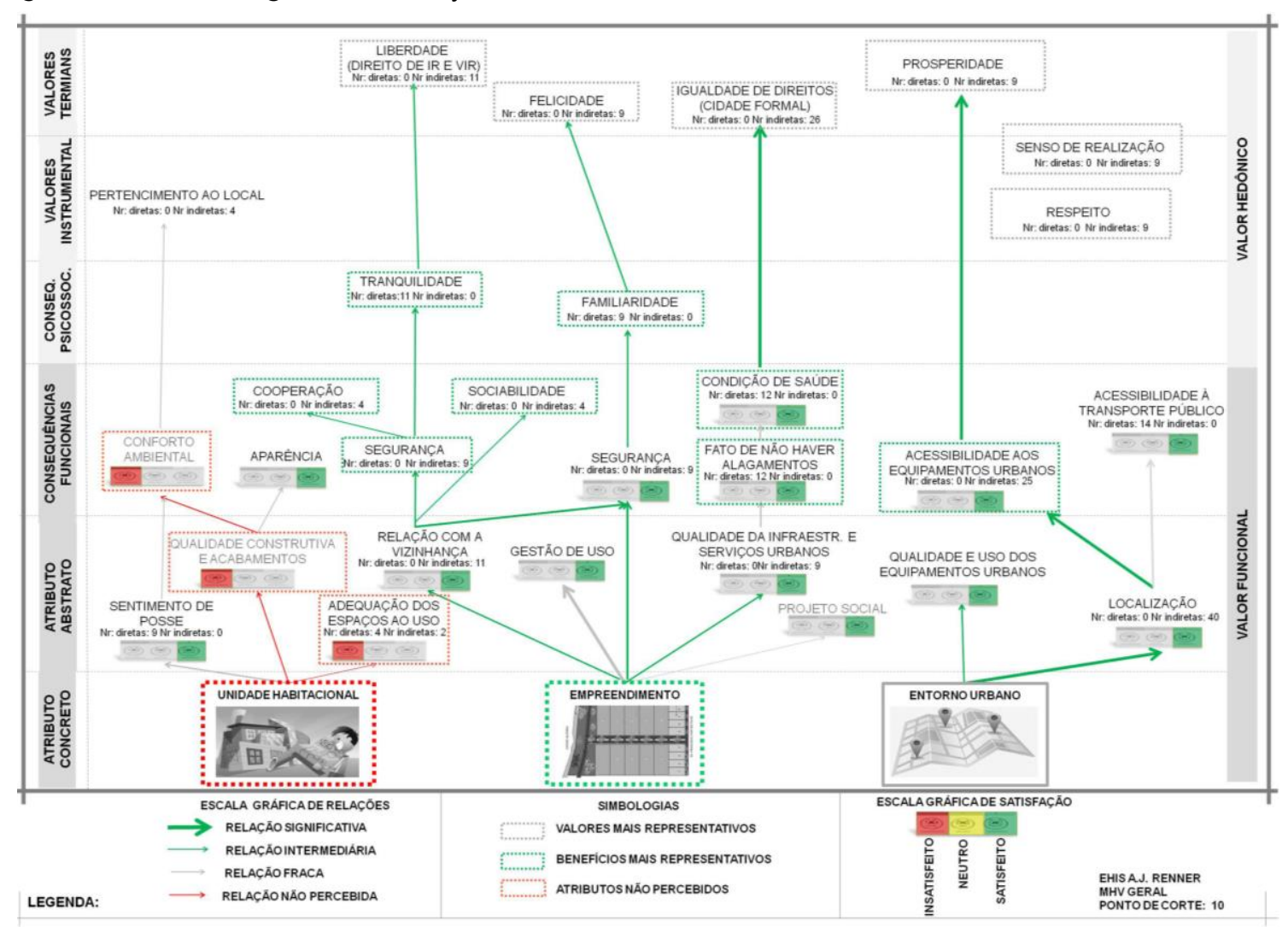


Figura 11 - Resultado geral da avaliação do estudo 2

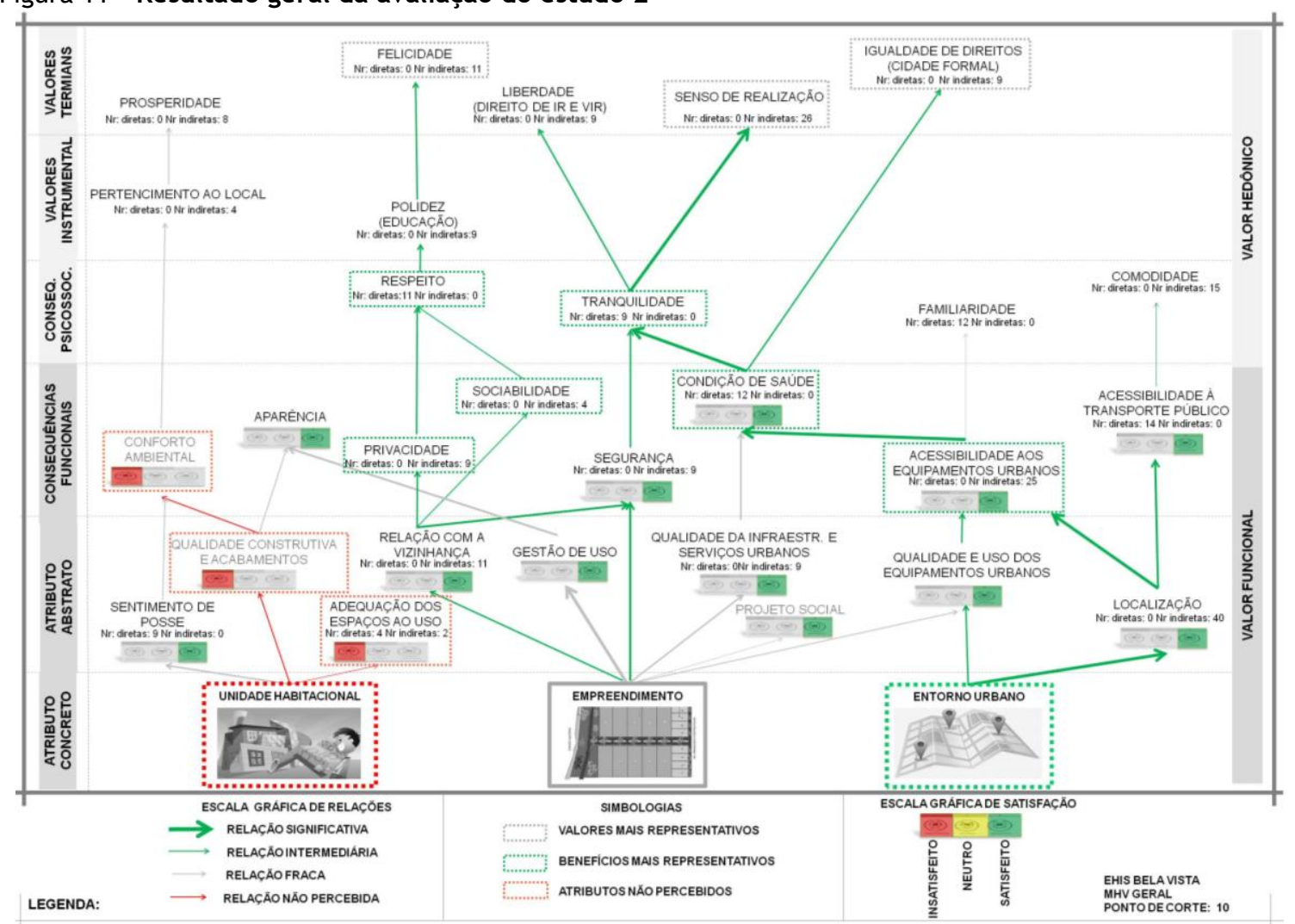

Figura 12 - Resultado geral da avaliação do estudo 3

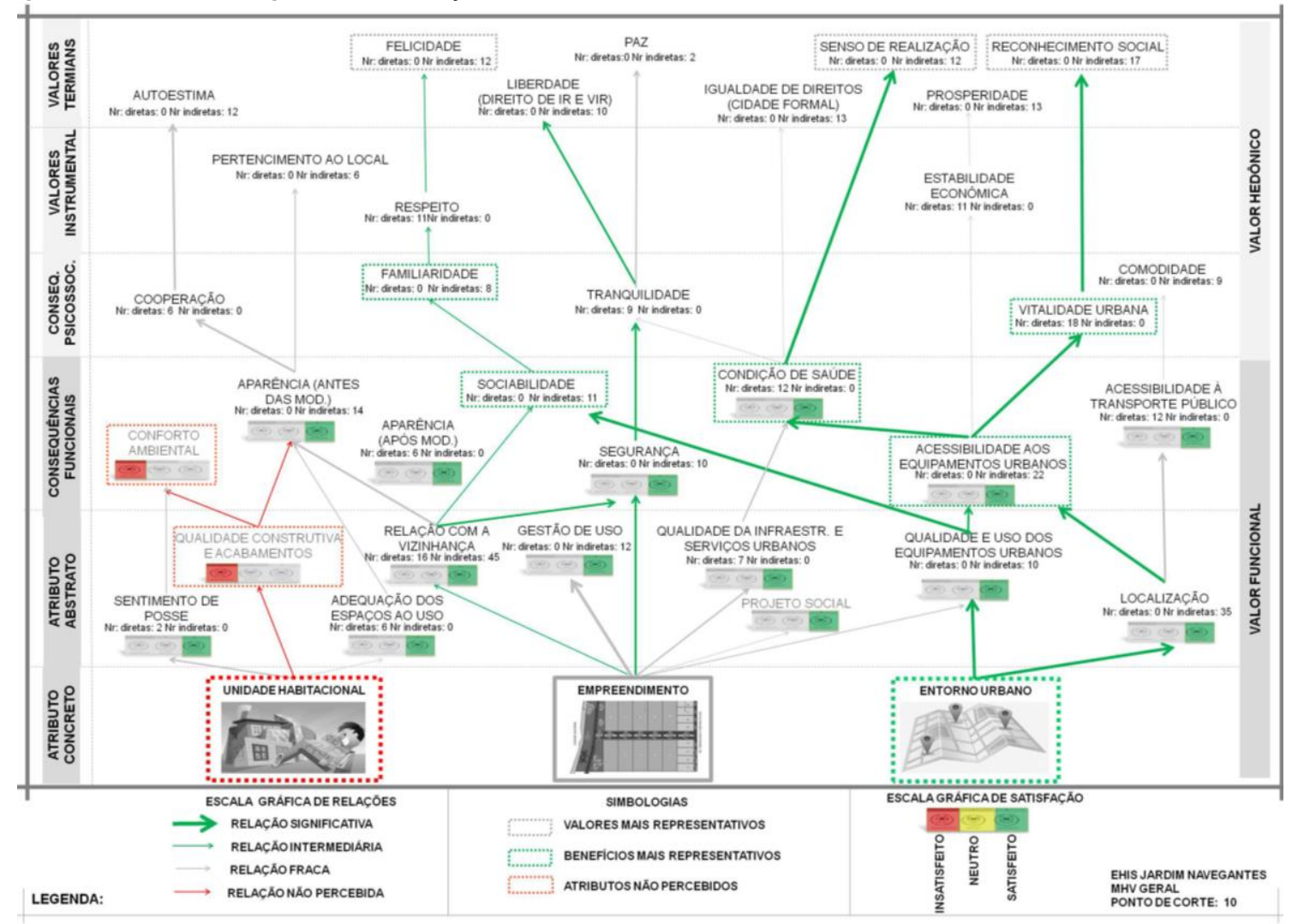


A comparação entre essas hierarquias de valor esperado com base na percepção dos técnicos da PMPA e as hierarquias de valor recebido com base na percepção dos usuários reforça o entendimento de que as percepções acerca do mesmo EHIS tendem a ser de natureza complexa e conflitante. A identificação e a explicitação desses conflitos por meio dos mapeamentos de hierarquia de valor podem auxiliar na compreensão de como os valores pessoais influenciam a percepção de valor dos distintos envolvidos no processo de desenvolvimento e uso de EHIS. A partir disso será possível para os técnicos a busca de alternativas que possibilitem maior geração de benefícios para os usuários de EHIS.

Nesse sentido, a aproximação entre essas diferentes percepções por meio de hierarquias de valor representa uma importante oportunidade para o direcionamento de estratégias internas ao programa, uma vez que possibilita parâmetros comparativos para identificar quais benefícios previstos não estão sendo efetivamente atingidos.

\section{Avaliação do método de avaliação}

Durante a discussão e disseminação dos resultados com os técnicos foi realizada a avaliação do método proposto, sendo essa a última etapa da pesquisa construtiva. Com base no estudo de Bonatto (2010), o Método de Avaliação proposto nesta pesquisa foi avaliado a partir da facilidade de:

(a) preparação;

(b) implementação; e

(c) análise das informações resultantes da avaliação pelos técnicos envolvidos no desenvolvimento dos EHIS investigados nos três estudos realizados.

A preparação da avaliação foi evidenciada como sendo a fase mais crítica em relação à facilidade de uso do método, já que muitos técnicos da PMPA nunca haviam sido inseridos no processo de avaliação de EHIS. Esse fato ocasionou um esforço adicional da equipe de pesquisa para que fossem realizadas discussões com os técnicos acerca de informações que pudessem auxiliar na preparação da avaliação. Tais discussões foram fundamentais para a estruturação das hierarquias de valor com base na percepção desses técnicos (valor esperado), as quais serviram como base para a construção de instrumentos de coleta específicos para a avaliação de cada EHIS.

Quanto à implementação das avaliações, foram realizados previamente treinamentos com as equipes de coleta, assim como testes piloto com os instrumentos de coleta estruturados para os três estudos realizados. Para a implementação da avaliação nos estudos 1 e 2 houve a participação de seis pesquisadores, enquanto no estudo 3 houve a participação de dois pesquisadores. Cabe salientar que nesta fase da pesquisa procurou-se inserir os técnicos da PMPA na avaliação, no entanto, em virtude do período de final de ano, não se obteve um retorno satisfatório.

A análise das informações resultantes das avaliações foi realizada com o apoio de estatísticos. Já as informações dos estudos 2 e 3 foram analisadas pelo pesquisador. De forma complementar, para as análises estatísticas do teste Kruskal Wallis contou-se com o apoio de um profissional da área de estatística durante as análises de resultados dos estudos 2 e 3 . Entre os três aspectos considerados para avaliar a facilidade de uso do Método de Avaliação, a análise das informações resultantes foi a que demandou mais tempo em virtude do menor número de pesquisadores envolvidos nessa fase da pesquisa.

A Tabela 2 permite que seja realizada uma análise do processo da avaliação, evidenciando uma possível melhora durante as fases de implementação. De modo geral, o estudo 3 apresenta redução no tempo despendido entre o treinamento para a coleta de dados e a efetiva apresentação para discussão e disseminação dos resultados obtidos nas avaliações em relação aos estudos 1 e 2

A Tabela 2 permite observar uma redução no tempo de treinamento das equipes para a coleta de dados, possivelmente em virtude da aprendizagem dessa fase nos estudos 1 e 2 . Já a implementação do estudo 3 durou cerca de 1 dia a mais do que nos estudos 1 e 2, como consequência do maior número de questionários aplicados aos usuários do estudo 3 , sendo esse o maior empreendimento avaliado. Redução no tempo despendido na apresentação para discussão e disseminação dos resultados pode ser evidenciada e possivelmente está relacionada à não necessidade de preparação do MHV para uma próxima avaliação. 
Tabela 2 - Análise geral do processo de avaliação nos três estudos realizados

\begin{tabular}{l|c|c|c}
\hline \multicolumn{1}{c|}{ ATIVIDADE } & ESTUDO 1 & ESTUDO 2 & ESTUDO 3 \\
\hline Montagem da avaliação & $2 \mathrm{~h}$ & $1 \mathrm{~h} 30 \mathrm{~min}$ & $1 \mathrm{~h}$ \\
\hline $\begin{array}{l}\text { Treinamento para a coleta } \\
\text { de dados }\end{array}$ & $30 \mathrm{~min}$ & $20 \mathrm{~min}$ & $15 \mathrm{~min}$ \\
\hline $\begin{array}{l}\text { Implementação da } \\
\text { avaliação }\end{array}$ & $\begin{array}{c}2 \text { dias }(6 \text { mestrandos e } \\
37 \text { questionários) }\end{array}$ & $\begin{array}{c}2 \text { dias }(4 \text { mestrandos e } \\
63 \text { questionários) }\end{array}$ & $\begin{array}{c}3 \text { dias }(2 \text { mestrandos } \\
\text { e } 80 \text { questionários })\end{array}$ \\
\hline $\begin{array}{l}\text { Análise de dados } \\
\text { pesquisador) }\end{array}$ & $\begin{array}{c}1 \text { semana (1 } \\
\text { pesquisador) }\end{array}$ & $\begin{array}{c}1 \text { semana }(1 \\
\text { pesquisador) }\end{array}$ \\
\hline $\begin{array}{l}\text { Apresentação para } \\
\text { discussão e disseminação } \\
\text { dos resultados }\end{array}$ & $\begin{array}{c}1 \mathrm{~h} 30 \text { min (auditório } \\
\text { do DEMHAB }\end{array}$ & $\begin{array}{c}1 \mathrm{~h} 30 \text { min (auditório } \\
\text { do DEMHAB) }\end{array}$ & $\begin{array}{c}1 \text { h (auditório do } \\
\text { DEMHAB) }\end{array}$ \\
\hline
\end{tabular}

\section{Considerações finais}

A presente pesquisa foi norteada pelo objetivo principal de apresentar um método proposto para avaliação da percepção de valor esperado pelos técnicos de instituições públicas e recebido pelos usuários de empreendimentos habitacionais de interesse social (EHIS) brasileiros. A principal contribuição da pesquisa é referente à proposta do Método de Avaliação, que combina, por meio do mapeamento de hierarquia de valor, a percepção de técnicos (valor esperado) envolvidos no desenvolvimento de EHIS com a percepção de usuários (valor recebido) envolvidos em sua ocupação.

O mapeamento hierárquico de valor estruturado a partir da percepção dos técnicos (valor esperado) foi abordado a partir de seis níveis de abstração, os quais possibilitaram maior detalhamento entre os níveis que compõem a hierarquia de valor, como recomendado por Gutman (1982). Os constructos identificados foram comparados com a revisão da literatura. $\mathrm{Na}$ base do modelo foram estruturados os atributos concretos e abstratos do EHIS, no nível intermediário do modelo foram estruturadas as consequências de uso funcionais e psicossociais, enquanto no topo do modelo foi estruturado o objetivo esperado pelo programa.

Foi possível observar nos MHV de percepção de valor esperado pelos técnicos que os atributos concretos e os objetivos esperados no contexto dos programas habitacionais brasileiros tendem a convergir, como já apontado por Bonatto (2010). Nesta pesquisa foi identificado que atributos abstratos e as consequências funcionais e psicossociais de uso esperadas pelos técnicos tendem a variar de acordo com o empreendimento avaliado. Na operacionalização do método, os níveis identificados foram utilizados como um banco de dados genéricos, o que possibilita a adição ou remoção desses constructos a cada empreendimento avaliado e denota o potencial de adaptação do método a distintos contextos de EHIS.

A estruturação do método proposto apresenta os passos necessários para a adição dos atributos do EHIS, das consequências de uso desse empreendimento e dos objetivos a serem alcançados pelo programa. Posteriormente, o método explicita a necessidade de adaptação do instrumento de coleta, na qual é adicionada a técnica de pesquisa laddering. Essa técnica permite que, por meio de entrevistas em profundidade com os usuários, sejam identificados os níveis mais abstratos de valor percebido presentes na estrutura cognitiva deles. Os dados qualitativos provenientes da técnica de pesquisa laddering foram estruturados em cinco fases com base no que recomendam Reynolds e Gutman (1988). Dessa forma, foi possível complementar os dados quantitativos do instrumento de coleta com dados qualitativos.

A combinação de técnicas quantitativas e qualitativas permitiu uma avaliação mais aprofundada ao identificar não apenas quais, mas também por que determinados elementos são mais importantes para a formação de valor do que outros, conforme apontam Veludo-de-Olveira e Ikeda (2005). No método proposto foram operacionalizados os passos para a coleta, análise e processamento tanto dos dados quantitativos quanto dos dados qualitativos da pesquisa. Ao término da aplicação do método os dispositivos visuais para apresentação dos resultados, especialmente os MHV da percepção dos usuários, buscam explicitar conjuntamente os resultados qualitativos e quantitativos sobrepostos.

Os estudos realizados nesta pesquisa evidenciaram especificidades e similaridades nas estruturas hierárquicas de valor resultantes das avaliações. No estudo 1, por exemplo, foi possível observar que os usuários tendem a perceber como principal benefício as consequências de uso vinculadas ao

${ }^{2}$ Departamento Municipal de Habitação. 
atributo concreto "empreendimento". Nos estudos 2 e 3 os principais benefícios percebidos pelos usuários tendem a estar relacionados ao atributo concreto "entorno urbano". De modo similar, o atributo concreto "unidade habitacional" representou nos três estudos realizados os benefícios menos percebidos, os maiores índices de insatisfação e os motivos mais representativos para a saída dos usuários dos empreendimentos avaliados, evidenciando, neste caso, oportunidades de melhorias para futuros empreendimentos.

Os mapeamentos hierárquicos de valor, com base no que foi esperado pelos técnicos, permitiram a comparação com os MHV do que foi percebido pelos usuários como efetivamente recebido na ocupação dos empreendimentos. Assim, os resultados desta pesquisa permitiram também evidenciar a importância de se avaliar a percepção de valor de ambas as esferas: de quem desenvolve e de quem usa os EHIS. Os MHV resultantes dessa análise, quando apresentado aos técnicos envolvidos no desenvolvimento de EHIS, permitiram que eles conseguissem identificar valores mais abstratos percebidos pelos usuários, insuficientemente explicitados por avaliações até então realizadas (MIRON, 2008; MIRON; FORMOSO, 2009; GRANJA et al., 2009; BONATTO, 2010). O mapeamento a partir da percepção dos usuários demonstrou que não apenas o objetivo apontado pelas pesquisas anteriores e pelos programas habitacionais brasileiros ("melhoria da qualidade de vida dos usuários") era muito genérico como também indicou de maneira mais explícita como os usuários efetivamente percebem esses valores (ex.: igualdade de direitos, liberdade, felicidade e prosperidade).

A discussão gerada nesta pesquisa sustenta a importância da consideração e aproximação da percepção de técnicos e de usuários, uma vez os resultados demonstraram que a convergência entre as percepções desses agentes pode estar relacionada a resultados mais satisfatórios. Nesse sentido, visando explorar a potencialidade desse tipo de avaliação para a melhoria de EHIS, futuras pesquisas podem contribuir a partir do refinamento do método (instrumento de coleta, análise, representação e apresentação de resultados), assim como para a inserção de avaliações no processo de desenvolvimento de outros EHIS brasileiros.

A aproximação entre essas diferentes percepções, por meio de hierarquias de valor, representa uma importante oportunidade para o monitoramento dos resultados de EHIS. Esse tipo de avaliação tende a possibilitar parâmetros comparativos para identificação dos benefícios que estão sendo efetivamente percebidos pelos usuários em relação aos benefícios esperados na implementação de programas habitacionais, assim como na explicitação dos níveis mais abstratos presentes na percepção dos usuários, os quais traduzem o objetivo utilizado em programas habitacionais brasileiros. Nesse sentido, a avaliação realizada nesta pesquisa pode auxiliar no refinamento do processo de desenvolvimento de EHIS para uma possível maior geração de valor aos usuários.

Por fim, o método proposto foi avaliado pelos técnicos a partir de sua facilidade de preparação, implementação e análise das informações resultantes. De modo geral, foi possível observar que o método desenvolvido atendeu aos propósitos da pesquisa, uma vez que foi considerado pelos técnicos de fácil uso e compreensão. De forma complementar, também foi possível observar durante $o$ desenvolvimento desta pesquisa o interesse dos técnicos nas informações resultantes para a melhoria do EHIS e emprego do método para avaliação de futuros empreendimentos de programas habitacionais.

\section{Referências}

BARLOW, J.; OZAKI, R. Achieving “Customer Focus" in Private Housebuilding: current practice and lessons from other industries. Housing

Studies, v. 18, n. 1, p. 87-101, 2003.

BOnATTO, F. S. Proposta de Um Modelo Para Avaliação de Empreendimentos Habitacionais de Interesse Social a Partir da Percepção de Clientes Finais. Porto Alegre: Universidade Federal do Rio Grande do Sul, 2010.

BONATTO, F.; MIRON, L.; FORMOSO, C. Avaliação de Empreendimentos Habitacionais de Interesse Social Com Base na Hierarquia de Valor Percebido pelo Usuário. Ambiente Construído, Porto Alegre, v. 11, n. 1, p. 67-83, jan./mar. 2011.

BRITO, J. N. S.; FORMOSO, C. T. Avaliação de Empreendimentos Habitacionais de Interesse Social Com Base no Valor Percebido Pelo Usuário. In: ENCONTRO NACIONAL DE TECNOLOGIA DO AMBIENTE CONSTRUÍDO, 2014, Maceió, AL. Anais... Maceió, 2014.

BRITO, J. N. S.; FORMOSO, C. T.; ROCHA, G. $\mathrm{S}$. Estudo da formação de valor de usuários finais de empreendimentos habitacionais de interesse social. In: ENCONTRO NACIONAL DE TECNOLOGIA DO AMBIENTE CONSTRUÍDO, 14., Juiz de Fora, 2012. Anais... Juiz de Fora, 2012. 
COOLEN, H.; HOEKSTRA, J. Values as Determinants of Preferences for Housing Attributes. Journal of Housing and Built Environment, v. 16, p. 285-306, 2001.

GRANJA, A. D. et al. A Natureza do Valor Desejado na Habitação Social. Ambiente Construído, Porto Alegre, v. 9, n. 2, p. 87-103, abr./jun. 2009.

GUTMAN, J. A. Means-End Chain Model Based on Consumer Categorization Processes. Journal of Marketing, v. 46, n. 2, p. 60-72, 1982.

HENTSCHKE, C. S. et al. A Method for Proposing Valued-Adding Attributes in Customized Housing. Sustainability, v. 6, p. 9244-9267, 2014.

KHALIFA, A. S. Customer Value: a review of recent literature and an integrative configuration. Management Decision, v. 42, n. 5, p. 645-666, 2004.

KOSKELA, L. An Exploration Towards a Production Theory and Its Application to Construction. Helsinki, 2000. 296 f. Tese (Doutorado em Tecnologia) - VTT Technical Research Centre of Finland, Helsinki, 2000.

LEINONEN, J.; HUOVILA, P. Requirements Management in Life-Cycle Design. Finland: VTT Building Technology, 2000.

LUKKA, K. The Constructive Research. In: OJALA, L.; HILMOLA, O-P. (Eds.). Case Study Research in Logistics. Turku School of Economics and Business Administration, 2003. Series B1.

MARQUES, L. M. PMCMV: análise da percepção de valor sobre as áreas comuns. Porto Alegre, 2015. Dissertação (Mestrado em Engenharia Civil) - Programa de Pós-Graduação em Planejamento Urbano e Regional, Universidade Federal do Rio Grande do Sul, Porto Alegre, 2015.

MIRON, L. I. G. Gerenciamento dos Requisitos dos Clientes de Empreendimentos

Habitacionais de Interesse Social: proposto para o programa integrado entrada da cidade em Porto Alegre/RS. Porto Alegre, 2008. 350 f. Tese (Doutorado em Engenharia Civil) - Escola de Engenharia, Universidade Federal do Rio Grande do Sul, Porto Alegre, 2008.

MIRON, L. I. G.; FORMOSO, C. T. Contribuições Conceituais do Marketing Para a Habitação de Interesse Social. In: ENCUENTRO LATINOAMERICANO DE GESTIÓN Y ECONOMÍA DE LA CONSTRUCCIÓN, 3., Bogotá, 2009. Proceedings... Bogotá: Universidad de los Andes, 2009.
MIRON, L. I. G.; TZORTZOPOULOS, P.; FORMOSO, C. T. Geração de Valor em Empreendimentos HIS: parcerias com o poder público. In: Qualidade Ambiental na Habitação: Avaliação Pós-Ocupação. São Paulo: Oficina de Textos, 2013.

MONTEIRO, D. A. B. Proposta de Um Método Para Avaliação da Percepção de Valor em Empreendimentos Habitacionais de Interesse Social. Porto Alegre, 2015. Dissertação (Mestrado em Planejamento Urbano e Regional) - Faculdade de Arquitetura, Universidade Federal do Rio Grande do Sul, Porto Alegre, 2015.

MONTEIRO, D. A. B. et al. Avaliação da Percepção de Valor em Empreendimentos Habitacionais de Interesse Social: perspectivas de técnicos e de usuários. Ambiente Construído, Porto Alegre, v. 15, n. 4, p. 37-53, out./dez. 2015.

MONTEIRO, D. A. B.; MIRON, L. I. G.

Avaliação da Retenção, Satisfação e Valor Percebido pelos Usuários de Empreendimentos Habitacionais de Interesse Social. Arquisur Revista, v. 10, p. 84-107, 2016.

MONTEIRO, D. A. B.; MIRON, L. I. G. Contribuições do Modelo Means-End Chain Para Retroalimentação de Dados em Empreendimentos Habitacionais de Interesse Social. Gestão \& Tecnologia de Projetos, v. 12, p. 69-84, 2017.

REYNOLDS, T. J.; GUTMAN, J. Laddering Theory, Method, Analysis, and Interpretation. Journal of Advertising Research, v. 28, p. 11-29, 1988.

REYNOLDS, T. J.; OLSON, J. C. Understanding Consumer Decision Making: the means-end approach to marketing and advertising strategy. London: Lawrence Erlbaum Associates, 2008.

SILVA, M. N. Percepção de Valor dos Usuários Sobre o Território: estudo de caso no bairro cidade baixa em Porto Alegre - RS. Porto Alegrer, 2015. Dissertação (Mestrado em Engenharia Civil) - Programa de Pós-Graduação em Planejamento Urbano e Regional, Universidade Federal do Rio Grande do Sul, Porto Alegre, 2015.

VELUDO-DE-OLIVEIRA, T. M.; IKEDA, A. Uso e Limitações do Método Laddering. Revista de Administração Mackenzie, v. 5, n. 1, p. 197 222, 2005.

WOODRUFF, R. B. Customer Value: the next source for competitive advantage. A Journal of Academy of Marketing Science, v. 25, p. 139153, 1997. 
ZINAS, B. Z.; JUSAN, M. M. Motivational Factors Influencing Housing Interior Finish Choice and Preference. Procedia - Social and Behavioral Sciences, v. 36, p. 177-186, 2012.

\section{Agradecimentos}

Os autores agradecem ao CNPq, à CAPES, à equipe técnica da PMPA e aos moradores dos EHIS avaliados.

\section{Deyvid Aléx de Bitencourt Monteiro}

Programa de Pós-Graduação em Planejamento Urbano e Regional | Universidade Federal do Rio Grande do Sul | Av. Sarmento Leite, 320, Centro | Porto Alegre - RS - Brasil | CEP 90050-170 | Tel.: (51) 3308-3145 | E-mail: deyvidalex@hotmail.com

\section{Luciana Inês Gomes Miron}

Programa de Pós-Graduação em Planejamento Urbano e Regional | Universidade Federal do Rio Grande do Sul | E-mail: luciana.miron@ufrgs.br

Revista Ambiente Construído Associação Nacional de Tecnologia do Ambiente Construído Av. Osvaldo Aranha, $99-3^{\circ}$ andar, Centro Porto Alegre - RS - Brasil CEP 90035-190

Telefone: +55 (51) 3308-4084 Fax: +55 (51) 3308-4054 www.seer.ufrgs.br/ambienteconstruido E-mail: ambienteconstruido@ufrgs.br 